\title{
The English Language Of Multitasking Librarian Candidates: Tips For Cultivating Interest In English Through Friendly Atmosphere Approach
}

\section{Bahasa Inggris Calon Pustakawan Multitasking: Kiat-Kiat Menumbuhkan Minat Berbahasa Inggris Melalui Pendekatan Ramah Suasana}

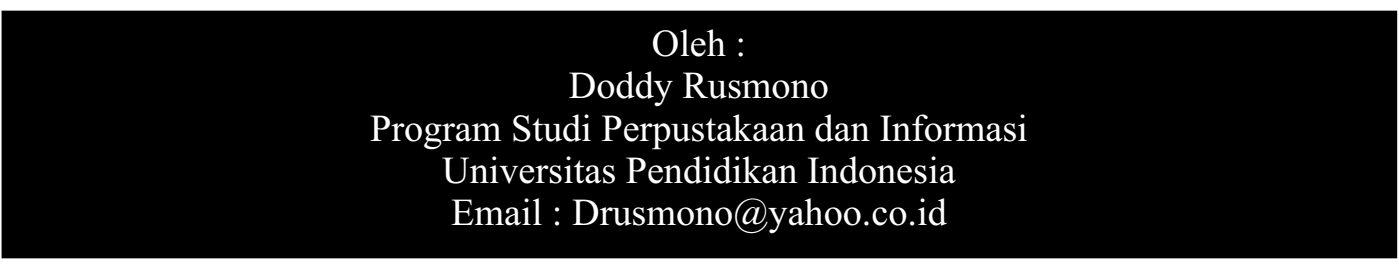

Abstract. Ideas expressed by LIS (Library and Information Science) students in the form of writing are incomprehensible to some extent. The work of LIS students of UPI, the librarians to-be, needs to be examined. These students are learners categorized as SNED (Students of Non English Department) gaining experience through learning English in the EFL (English as a Foreign Language) environments worth investigating. Lack of skill to bridge a gap between their native language (Indonesian) and target language (English) creates a room for inadequacy especially to native speakers. Paragraphs written by these

students as ELLs (English Language Learners) are not easily understood due to the constraints dealing with linguistic and cultural barriers. A very small number of students have been willing to write their answers in English language when it comes to options of answering in English or answering in Indonesian language in the mid-term

examination. This phenomenon gives a picture of competency in expresing ideas in English which is still far from being sufficient. Approach using a qualitative method of research with interview and observation as instruments to collect data from informants results in facts that they lack of confidence leading to an impact factor of low quality of writing. Hence, facilitators should take necessary steps to help with warm and friendly conduct toward betterments in working out English instead of Indonesian English. Librarians as professionals in practice should have a good command of English and exercise it in their daily routines. Their "at-homeness" proves to be very low making it possible for a native speaker to misinterpret the original ideas of the ELLs. Culture as a factor influences and builds a sense, attitude, and response of the ELLs in interacting with a native speaker of the target language. It is found out that efforts with friendliness and pleasing approach by the facilitators to make the ELLs feel comfortable plays an important part toward betterments.

Key words: friendly atmosphere, paragraph writing, linguistic consraints, culture, SNED.

\begin{abstract}
Abstrak. Gagasan yang disampaikan dalam bentuk tertulis menggunakan Bahasa Inggris oleh Mahasiswa Program Studi Perpustakaan FIP-UPI, yang adalah calon Pustakawan, memerlukan penelitian. Para Mahasiswa ini adalah pembelajar yang berkategori SNED (Students of Non-English Department) yang belajar Bahasa Inggris dengan lingkungan EFL (English as a Foreign Language) yang menarik untuk diteliti. Kekurangmampuan menjembatani kesenjangan antara Bahasa Ibu mereka (Bahasa Indonesia) dengan Bahasa

Penerima (Bahasa Inggris) menghambat keberterimaan oleh khususnya Penutur Asli (native speaker). Paragraf karya tulis SNED sebagai Pembelajar Bahasa Inggris (ELLs -
\end{abstract}


English Language Learners) sering sulit dimengerti karena kendala linguistik dan kultur. Sedikit sekali Mahasiswa yang mau menulis didalam Bahasa Inggris pada UTS (Ujian

Tengah Semester). Kenyataan ini menggambarkan betapa kemampuan Mahasiswa menyusun kalimat masih jauh dari memadai. Pendekatan menggunakan metode kualitatif dengan intrumen wawancara bersama informan menghasilkan simpulan bahwa lack of confidence onthe students' part merupakan impact factor. Teramati bahwa Bahasa Inggris yang digunakan masih merupakan Bahasa Inggris "Indonesia". Pada prakteknya, status Pustakawan Multitasking menuntut profesional Pustakawan untuk dapat berbahasa Inggris didalam rutinitas kesehariannya. Dalam hal ini, "at-homeness" mereka masih rendah sehingga seorang native speaker yang mencoba memahami bahasa tulisan karya Pustakawan melakukan penafsiran yang keliru. Selain itu, pengetahuan ELLs mengenai kultur sasaran (Bahasa Inggris) memainkan peran sangat penting didalam berkomunikasi. Didalam menyampaikan gagasan mereka, para pembelajar ini mengalami kesulitan karena terkendala oleh kultur bahasa sasaran. Kultur ini mempengaruhi dan membentuk perasaan, sikap, dan respon ELLs didalam berinteraksi dengan penutur asli bahasa sasaran.

Ditemukan bahwa upaya yang ramah dan menyenangkan dari pengajar selaku fasilitator untuk memperbaiki Bahasa Inggris para calon Pustakawan ini merupakan suatu keniscayaan.

Kata kunci: ramah suasana, penulisan paragraf, kendala linguistik, kultur, SNED,. 


\section{PENDAHULUAN}

$\mathrm{P}$ engajaran Bahasa Inggris sebagai Bahasa Asing (EFL English as a Foreigh Language) bagi para Mahasiswa Bukan Jurusan Bahasa Inggris (SNED - Students of Non-English Department) memerlukan pendekatan khusus agar mereka terdorong menulis paragraf didalam Bahasa Inggris (B.Ing.) dengan cara yang lebih patut. Salah satu SNED pada Fakultas Ilmu Pendidikan (FIP) Universitas Pendidikan Indonesia (UPI) adalah para Mahasiswa Program Studi Perpustakaan dan Sains Informasi. Untuk memperoleh dampak positif dari proses belajar melalui perkuliahan Bahasa Inggris 1 dan Bahasa Inggris 2 bagi Mahasiswa kategori ini, misalnya, metode pembelajaran yang dikembangkan melalui pendekatan yang cocok merupakan sesuatu yang mendesak. Karena tidak merasa "at home" baik dalam kedua kultur yang berbeda, para Mahasiswa SNED ini menhasilkan tulisan yang sukar untuk dimengerti. Mereka kurang begitu paham tentang bahasa sasaran (B.Ing.) sebagai fenomena yang hidup ketika mengalihkan gagasan mereka dalam bentuk tulisan. Sehingga, kecil sekali pemahaman mereka akan pentingnya pembaca sasaran yang akan memahami arti yang disuguhkan. Arti yang disuguhkan tadi hanyalah merupakan nama-nama objek dan berbagai tindak yang menyertainya.
Mereka kurang menyertakan perasaan, sikap, dan rasa percaya bahwa mereka sedang menyampaikan gagasan. Kultur bahasa asing memang tidak benar-benar menyatu didalam gagasan yang mereka tuliskan. Salah seorang Mahasiswa yang menulis, misalnya, "The circle way is difficult for explain, but in a side of picture. This way used for take the key words or conclusing this paragraph" tidak menyampaikan pesan seberarti seperti yang dimaksud oleh sang penyampai gagas sebenar-benarnya (Rusmono, 2011:77). Bagi seorang penutur asli (native speaker), gagasan tadi tidak membuatnya mengerti apa sebenarnya yang dimaksud. Mahasiswa tadi pasti ingin menyampaikan gagasan yang berbunyi "It is difficult to explain how the circle way works when reading. The illustration below shows the use of key words to make a conclusion of the paragraphs". Nampaknya Mahasiswa ini kurang familier dengan kultur dimana bahasa itu digunakan dengan masyarakat yang menggunakan bahasa itu dengan cara, adat istiadat, kepercayaan, dan semua hal yang membentuk kultur (Sofer, 1996:24).

Para pembelajar Bahasa Inggris (ELLs - English Language Learners) sebaiknya memahami bagaimana mengekspresikan gagasannya ketika menulis dengan cara melibatkan dirinya secara utuh dan menyeluruh. Hill dan Flynn (2006:2) menyatakan Language is 
the air we breathe and the water in which we swim. It comes as naturally to us as seeing the sky or digesting our food. It is as vital a part of our name and personality. But what if we suddenly had to had to breathe different air or swim in different water? Kultur dimana ELLs hidup mempengaruhi dan membentuk perasaan, sikap, dan respon ELLs yang kelak akan menghubungkannya dengan pengalaman dan interaksinya pada pembaca sasaran. Para pakar juga mengatakan bahwa bahas a mencerminkan kultur karena kata-kata merujuk pada kultur seperti misalnya kepercayaan yang tumbuh di masyarakat beserta praktek-prakteknya. Namun demikian, pencerminannya tidak pernah lengkap ataupun sempurna. ELLs memang perlu menyadari bahwa apa yang mudah dipahami didalam Bahasanya (Bahasa Indonesia - B.Ind.) sangat mungkin akan sukar dipahami didalam B.Ing. Mereka terkendala dalam berekspresi menggunakan B.Ing. karena relativitas kuktural: upaya mereka untuk membuat pembacanya paham apa yang mereka ingin sampaikan ternyata berujung kesia-siaan. SNED sebagai ELLs seyogiyanya fasih baik didalam mengungkakan gagasan mereka dan mengetahui persis siapa sang penerima pesan. Sehingga, komunikasi berjalan mulus, akurat, jelas, dan alamiah.

\section{Metode Penelitian}

Penelitian ini menggunakan pendekatan kualitatif yang bertujuan untuk mengidentifikasi dan menggambarkan fenomena sebelum dilakukan analisis. Stark and Torrance (2006:27) mengatakan bahwa ....case study assumes that social activity is created through social interaction, albeit situated in particular contexts and histories, and seeks to identify and describe before trying to analyse and theorize. Corak penulisan paragraf didalam B.Ing. yang teranalisis menyertakan pengukuran-pngukuran atas fenomena kultur sumber dan kultur sasaran. Perolehan kata-kata B.Ing sebagai bahasa asing oleh ELLs juga layak untuk diteliti melalui peggunaan sumber-sumber bukti bertingkat (Yin, 1981:91). Alasan dan cara yang dipilih dalam hal menulis yang berkualitas dibahas secara induktif untuk menumbuhkan pemahaman. Tujuan akhir penelitian ini adalah mengidentifikasi derajat kepercayaan diri Mahasiswa SNED ketika penuangan gagasan berlangsung. Pencerahan yang mengungkap fenomena ini merupakan titik pembelajaran untuk mencapai betterments.

\section{Permasalahan}

Menyampaikan gagasan yang bersumber dari "dalam negeri" kepada penerima pesan yang lahir, tumbuh dan 
berkembang di "kultur sana" beresiko patahnya arti yang dikandung didalam pesan tadi. Kaur (2006:77) menekankan bahwa ELLs harus dapat menyampaikan gagasannya dalam bentuk tertulis sesuai dengan rambu-rambu, gaya, dan butirbutir gramatikal dari bahasa sasaran (B.Ing.) agar pesan mereka terhindar dari kesan kaku dan tidak alamiah. Makna yang berterima kemudian menjadi mudah dicerna dan tidak menyimpangi jiwa gagasan.

\section{Alamiah dan berterima}

Ungkapan di atas mencerminkan betapa menantangnya penggunaan B.Ing. didalam mengekspresikan gagasan: keaslian yang selaras dengan kultur dan keberterimaan yang utuh. Salah satunya adalah bahwa ELLs memang harus terlebih dahulu memiliki, misalnya, kosa kata dalam jumlah yang memadai dan mengerti serba cukup rambu-rambu gramatika seperti misalnya rumusan 9BP+3C (Cd., Cx., Cdx) dan PoS, yaitu 9 Basic Patterns and 3 Compounds (Compound, Complex, Compound Complex) dan Parts of Speech. Satu kata, friend, sebagai kata kunci, misalnya, mempunyai lima kata relasi yaitu companion, ally, close acquintance, crony, dan confidant. Bagi ELLs, kelima kata relasi tersebut terasa "baru" yang berarti ketika mereka menemukannya didalam suatu teks, mereka tidak akan pernah menhetahui bahwa kelima "kata baru" tadi mempunyai arti yang sama ataupun mirip dengan kata "friend". Sebenarnya, tehnik memperoleh kosa kata dengan cepat dapat membantu mereka memperkaya kosa kata didalam waktu yang singkat. Pengayaan ini akan secara alamiah mengarah kepada pilihan kata yang tepat untuk mengungkapkan gagasan secara akurat agar diperoleh keberterimaan yang tepat dari pihak penerima pesan.

\section{Alam pembelajaran}

Pengetahuan ELLs tentang kultur sasaran masih sedemikian minim sehingga penguasaan gramatika dan kosa kata semata tidak cukup menjamin berhasilnya penyampaian gagasan didalam Bahasa Ibu kedalam Bahasa Asing, Inggris, dalam hal ini. Cakir (2006:59) menguatkan bahwa "Most frequently confronted that students to a great extent know the rules of language, but are not knowledgeable enough about the target culture". Sebagai alat komunikasi, dua arus paralel menyadarkan pikiran ELLs yang seharusnya mencermati adanya perbedaan dua bahasa dan membuatnya harus menghadapi kendala sosiokultural dan sosiolinguistik.

Di dalam pembelajaran B.Ing. sebagai bahasa kedua (ESL - English as a Second Language) sperti yang terjadi di Singapur, misalnya, ELLs terlibat didalam penggunaan B.Ing. secara 
alamiah didalam kehidupan sehariharinya. Di Indonesia, ELLs berada didalam alam pembelajaran dengan konteks B.Ing. sebagai bahasa asing (EFL) yang berarti bahwa perolehan B.Ing. tergantung pada struktur pembelajaran di ruang kelas dan terbatas oleh sempitnya cakupan makna dengan segala dampak negatifnya (Macau, 2003:149). Benarlah adanya bahwa salah satu kelemahan didalam penggunaan bahasa adalah ketika suatu gagasan dikemukakan, kecenderunag emosional dan penyimpangan secra alamiah sering terjadi.

\section{PEMBAHASAN}

Menghafal rumusan gramatika untuk kemudian menerapkannya didalam kalimat yang mudah dimengerti merupakan tantangan. Seorang peneliti kebahasaan pernah menemukan kenyataan bahwa mereka yang terbiasa dengan penggunaan rumus-rumus kimia akan lebih mudah menerapkan ramburambu gramatika kedalam susunan kalimat yang runtut dan logis karena bahasa bekerja dengan aksioma, sama seperti halnya Ilmu Kimia.

\section{Perolehan kosa kata}

Menghafalkan senarai kosa kata dapat dipermudah dengan tehnik RPVA (Rapid Passive Vocabulary Acquisition) yaitu pemertamaan satu kata populer membuahkan lima kata yang tidak populer tetapi bermakna sama, seperti contoh kata "friend" di atas. Tiga daftar kata yang masing-masing berisi duabelas kata kunci, misalnya, akan menantang daya hafal ELLs, yang akan menghasilkan perolehan 180 kata dalam waktu singkat melalui 3X12X5 yang artinya tiga daftar kata berisikan duabelas kata kunci yang akan dikalikan dengan lima kata relasi. Tehnik lain ELLs mungkin akan menjadikannya tantangan adalah dengan "memainkan" kata melalui paraphrasing yaitu menerjemahkan arti sebuah kalimat melalui ketrerampilan memainkan derivatives (kata jadian) ataupu PoS (Parts of Speech - Bagian Kata). PoS ini sangat berguna untuk menjadikan kalimat yang sulit dan rumit menjadi mudah dan bermakna. PoS terutama terdiri dari Noun, Verb, Adjective, dan Adverb (Kata Benda, Kata Kerja, Kata Sifat, dan Kata Keterangan). Tehnik memparafrase menggunakan gaya menerjemahkan dengan cara yang menyenangkan karena tujuan utama memparafrase adalah membuat suatu kalimat menjadi mudah untuk dipahami, ataupun membuat suatu ujaran lebih komunikatif. Kata "beautiful", misalnya, mempunyai padanan kata seperti lovely, gorgeous, pretty, cute, dan smashing. Untuk menulis kalimat Dwi Retno is the most beautiful student in this class, misalnya, kelima padanan kata beautiful dapat disubstitusikan, sehingga kalimatnya menjadi Dwi Retno is the loveliest student 
in this class. Atau, melalui penggunaan derivatives dengan cara mengubah kata sifat beautiful menjadi kata benda beauty, yang walaupun disusunkan berbeda, akan mempunyai arti yang sama: Dwi Retno's beauty is incomparable in this class. Atau, Nobody is pretty in this class but Dwi Retno. Memadukan kosa kata dengan gramatika berpotensi menjanjikan dalam hal menulis dengan baik dan benar (Rusmono, 2015:69).

\section{Peran fasilitator}

Dosen, Guru, Instruktur, atau Pengampu berperan besar didalam "melembutkan" suara mengoreksi kekeliruan pembelajar sebagai ELLs. Pemojokkan secara terang-terangan akan mematikan semangat belajarnya. Seorang Instruktur dengan kapasitas fasilitator perlu selalu berupaya untuk menyiasati ketidakpatutan yang diperlihatkan oleh susunan kalimat yang dihasilkan oleh ELLs. Kalimat demi kalimat yang membentuk paragraf berkemungkinan "cacat arti" dalam artian jauh dari bermakna. Namun demikian, ketakbermaknaan itu sering terjadi karen ketidaksengajaan, dan oleh karenanya membutuhkan permakluman dari fasilitator. Kesamaan didalam komunikasi berbentuk verbal, untuk perbandingan, juga tak terhindarkan. Bagi ELLs Indonesia, untuk menciptakan "iklim Inggris" sangatlah penuh tantangan. Keadaan ini paling sering terjadi ketika openggunaan B.Ing. dipaksakan di lingkungan umum. ELLs yang bahasa daerahnya adalah Sunda, misalnya, beresiko besar manakala menggunakan B.Ing. untuk berkomunikasi dengan teman-temannya yang memiliki "penguasaan" yang sama tentang B.Ing. didepan orang-orang yang pandai menggunakan B.Ing. Para penutur B.Ing. dengan kelokalannya yang kental ini ingin dirinya dimengerti secara wajar, tetapi keberterimaan dengan cara yang "wajar" didalam kultur sasaran terwarnai olehunsur lokalitas seperti misalnya pengucapan kata. Benarlah adanya bahwa pengucapan nsatu orang dengan orang lainnya akan tidak persis sama. Seorang pakar pengucapan pernah berkata "No two people pronounce exactly alike". Perbedaan-perbedaan diantara individu terjadi karena berbagai penyebab seperti misalnya aspek lokalitas, pengaruhpengaruh awal, dan kehidupan sosial dari orang-orang disekitar tempat tertentu yang membentuk lingkungan yang khas. Belum lagi keberlainan perorangan yang sulit untuk dibahas ataupu didiskusikan.

\section{Potensi memproduksi ketidakpersisan}

Bagian yang kurang begitu mudah dipahami dari gagasan ELLs yang diekspresikan dalam bentuk tulisan bisa terjadi tanpa kesadarannya. Upaya untuk membaikkan oleh fasilitator sebaiknya untuk tujuan menghindarkan ELLs dari kemungkinan dipermalukan, terlebih 
penggunaan bahasa yang menyudutkan. Upaya penghindaran ini perlu dilakukan mengingat adanya kemungkinan timbul rasa kurang percaya diri yang mendalam. Dengan cara ini ELLs akan merasa aman dan berangapan dirinya terbebas dari segala bentuk intimidasi. Mereka akan melihat adanya kesempatan yang besar untuk mendapatkan akses ke pencerahan yang menyenangkan hatinya yang semakin mendorong semangatnya tanpa ragu-ragu mengekspresikasn gagasannya dalam bentuk tulisan .

ELLs tidak menghiraukan teori dan peraturan tulis-menulis ketika mereka menyusun kalimat-kalimat didalam sebuah paragraf. Selain tidak persis dalam hal merujuk empat jenis tulisan (argumentatif, deskriptif, ekspositori, naratif), kalimat topik didalam pragraf tidak diikuti oleh kalimat-kalimat pendukung yang harus saling erat berkaitan satu sama lainnya agar terbentuk koherensi. Agak lebih mencemaskan adalah bahwa gagasan yang diekspresikan untuk menyampaikan pesan masih jauh dari informatif. Baker (1992:47-62) mengingatkan bahwa suatu gagasan seharusnya dapat dimaknai dalam bentuk konfigurasi yang harus digambarkan dalam bentuk gagasan. Jelas tampak dari tulisan ELLs bahwa mereka memainkan peran sebagai pemula didalam hal menulis dan menghadapi kesulitan kareena mereka harus menyiapkan butir-butir pesan yang sepadan dalam arti dan utuh dalam arti, yaitu menyajikan kesepadanan yang dapat dikenali didalam kultur bahasa sasaran. Ada kecenderungan bahwa ELLs tidak menganalisa dan menggambarkan kesepadanan kognitif dari pesan yang disampaikan. Selain itu, ELLs tidak memandang pembacanya dari perspektif pemahaman monolingual pesan tertulis bagi pembacanya atas pesan yang tertulis agar menjadikan pesan itu menarik dan elegan: gagasan yang diekspresikan perlu dibuat bahan yang menyenagkan untuk dibaca.

Dalam batas-batas tertentu, ELLs menyimpangi teori penulisan akademik, yang artinya adalah mereka mengalihkan gagasan mereka didalam bahasa asli sekehendak hatinya, dan ada kesan mereka berpikiran bahwa teori-teori lebih implisit sifatnya daripada eksplisit. Sebagian besar dari ELLs dari studi kasus ini menunjukkan bahwa mereka seperti tidak membutuhkan teori penulisan: teori tidak perlu dipelajari. Apa yang dapat disimpulkan dari fenomena ini adalah bahwa ELLs secara reguler dan konsisten menyimpangi begitu banyak aturan yang ditetapkan oleh para ahli teori. Merujuk pada susahnya menerapkan teori menulis, terbukti juga bahwa ELLs menyadari "keIndonesiaannya" sehingga sering diperlukan ilustrasi untuk menggambarkan maksud pesan yang mereka ingin sampaikan.

Sebuah naskah karya ELLs yang 
berkategori SNED ditemukan seperti dibawah ini.

Okey guys, this is Multimedia Room. There is place for browsing, searching, downloading, and typing. All facilities this room free for user. And this is postgraduate room. We can access in repository upifor see this collection. Now, we will wend second floor. This library have relict deposits. Okay, this is magazine and France Corner. This room will be relaxing for user. And than user can copy essay, thesis, disertasi and other collection in foto copy room. Free from copy can using preservation of collection.

Semua bagian dari naskah di atas disalin persis seperti aslinya ketika ditulis oleh ELLs. Bagi sesama Mahasiswa yang datang dari negara berbahasa Inggris seperti Amerika Serikat dan Kanada, misalnya, penjelasan tehnis tentang bagaimana caranya menggunakan alat penelusur informasi secara elektronik untuk mengakses sumber-sumbver informasi di perpustakaan berkemungkinan tidak jelas kareena pemaparannya tidak didukung oleh diksi yang tepat dan cukup dapat dimengerti. Dua paragraf yang dikembangkan oleh salah seorang Mahasiswa ELLs tertera seperti dibawah ini.

\section{Hiking in Kramat Mountain}

Last week, I and my group gone to Kramat Mountain in West Java. Me and six of my friend have prepared everything that we need and can we bought to Kramat Mountain. In Friday, we started our vacation from Indonesia Education
University with a vehicle called ELF. We arrived in Circle Village at 05.00 P.M. So, we chosed to maked a tent for sleep. In the night, we cooked some food for diner. And then we sleep to keep our stamina.

In the morning, we prepared to hike Kramat Mountain. We started oour journaey in 08.00 A.M. At 11.30 A.M. we arrived the top of Kramat Mountain. We ate some snack and take photos in the top of Kramat Mountain. At 1.30 P.M. we chose to down the mountain. At 5.30 P.M. we arrived in Jaya Giri, Lembang. And we search a vehicle to brought we to campuss.

Kedua paragraf di atas penuh dengan sejumlah kekeliruan yang dilakukan dengan tidak sengaja. Ketika sang informan studi kasus yang adalah masih juga ELLs diwawancara, ternyata dimaksudditemukan bahwa sebenarnya ELLs ingin menulis dengan benar dan komunikatif. Namun demikian, penutur asli B.Ing. akan sangat sulit memahami apa yang sebenarnya dimaksud oleh pesan itu karena kosa kata yang dipilih secara tidak tepat dan gramatika yang tidak benar.

\section{SIMPULAN}

Mengupayakan agar niat baik SNED sebagai ELLs untuk menulis dalam B.Ing. terangkat dan tersalurkan dengan baik tidaklah akan pernah sia-sia. Para Dosen yang memainkan peran sebagai fasilitator yang mendekati Mahasiswanya dengan antusiasme menghasilkan respon yang positif dan berakhir dengan perbaikan di berbagai aspek. Celah yang diberikan untuk mengisi ruang yang 
kosong antara kultur bahasa ELLs sendiri dengan kultur bahasa asing boleh jadi masihjauh dari semourna. Namun demikian, setidak-tidaknya sebuah inisiatif yang inspiratif telah diluncurkan dan diharapkan dapat membawa perbaikan-perbaikan yang bermakna di masa datang. Memberikan kredit kepada Ells atas kerja keras yang ditunjukkan terbukti berujung harapan. Arah yang tersaji kemudian adalah kepercayaan diri yang membesar yang sejalan dengan berjalannya waktu akan menumbuhkan komunikasi yang dapat dipahami melalui karya tulis. Rasa percaya diri yang besar dan keyakinan bahwa menulis bukanlah hal yang mudah dapat mendorong ELLs untuk terus belajar dan berlatih. Dampak yang berpotensi menjanjikan dalam hal pengembangan dan implementasinya melalui innovasi merupakan butir pembelajaran.

\section{Daftar Pustaka}

Allen, WS. 1974. Living English Structures.5th ed. Aylesbury, Bucks: Hazel Watson \& Viney Ltd.

Baker, M. 1992. In Other Words: a course book on translation. London: Routledge.

Cakir, I. 2006. Developing Cultural Awareness in Foreign Language Teaching. Turkish Onlinejournal of D is tance Ed ucation TOJDE.vol.7\#3.

Garcia, Fredi et.al. 2014. Cross Cultural, Values and Ethics Differernces and Similarities between the US and Asian Countries.available at www.emeraldinsight.com/17468779.htm.

Hill and Flynn. 2006. Classroom Instruction that Works with English Language Learners. Alexandria: ASCD.

Kaur, K. 2006. A competent Translator and and Effective Knowledge Transfer. Kuala Lumpur: University of Malaya Press.

Macau, CM. 2003. Through Translation: considering multiple intellegencies. London: Oxford University Press.

Nababan, MR. 2007. Translation Process and Strategies: two case studies.

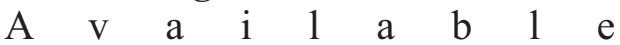
online:usd.ac.id/06/pub/_dosen/phe nomena/feb 07/nababan.pdf.

Nord, C. 1977. Translating as a Purposeful Activity: functional approaches explained.Manchester: St. Jerome.

Palfreyman, David and Richard C. Smith.eds. 2003. Learner Autonomy across Cultures.Language Education Perspectives. New York: Palgrave macmiltd.

Rusmono, Doddy. 2011. An investigation of Librarians' Translating Ability (A case studyat an Indonesian University). Disertasi tidak dipublikasikan. Bandung: Sekolah Pascasarjana Press.

Rusmono, Doddy. 2015. Transfer of Ideas with Semantic and Cultural Barriers by $S N$ in a Paragraph Writing. EduLIB.No.1.vol.4, Mei.

Sofer, M. 1996. The Translator's Handbook. Rockville: Schreiber Publishing.

Stark and Torrance.2005. Research Methods in The Social Sciences. London: S A GE Publication.

Trifonas, Peter Pericles.ed. 2005. Communities of Difference: culture, language, technnology. New York: 